\title{
Mesozoic giant fleas from northeastern China (Siphonaptera): Taxonomy and implications for palaeodiversity
}

\author{
HUANG DiYing ${ }^{1 *}$, ENGEL Michael S $^{2}$, CAI ChenYang ${ }^{1} \&$ NEL André ${ }^{3}$ \\ ${ }^{1}$ State Key Laboratory of Palaeobiology and Stratigraphy, Nanjing Institute of Geology and Palaeontology, Chinese Academy of Sciences, \\ Nanjing 210008, China; \\ ${ }^{2}$ Division of Entomology, Natural History Museum, and Department of Ecology \& Evolutionary Biology, University of Kansas, \\ Kansas 66045, USA; \\ ${ }^{3}$ CNRS UMR 7205, CP 50, Entomologie, Muséum National d'Histoire Naturelle, Paris F-75005, France
}

Received June 25, 2012; accepted October 8, 2012; published online March 22, 2013

\begin{abstract}
The recently discovered definite giant fleas from the Middle Jurassic Daohugou fauna and the Early Cretaceous Jehol fauna of northeastern China represent significant evidence for understanding ectoparasitism in the Mesozoic as well as the evolution of these giant blood feeders with their putative hosts (i.e. hairy or feathered vertebrates). On the basis of seven well-preserved specimens from Daohugou and Huangbanjigou we analyse the systematic classification of these primitive fleas, establishing two new genera and three new species as Pseudopulex wangi sp. nov., Hadropsylla sinica gen. et sp. nov., and Tyrannopsylla beipiaoensis gen. et sp. nov. All of them are assigned to the extinct siphonapteran family Pseudopulicidae, while the Early Cretaceous genus Tarwinia is transferred to Tarwiniidae fam. nov. The basal morphological disparities of Siphonaptera in the Mesozoic are evidenced by the occurrence of at least three distinct groups (pseudopulicids, tarwiniids, and saurophthirids). These disparate morphologies likely indicate adaptations to different hosts.
\end{abstract}

Mesozoic, flea, Pseudopulicidae, Tarwiniidae, diversity, ectoparasitism, Daohugou fauna, Jehol fauna

Citation: Huang D Y, Engel M S, Cai C Y, et al. Mesozoic giant fleas from northeastern China (Siphonaptera): Taxonomy and implications for palaeodiversity. Chin Sci Bull, 2013, 58: 1682-1690, doi: 10.1007/s11434-013-5769-3

Fleas (Siphonaptera) and true lice (Phthiraptera) are two major lineages of widely known ectoparasitic insects, infamous for the devastating effects select species have had on human affairs. Fleas, specialized for feeding on the blood of birds or mammals, comprise ca. 2500 described species in 16 extant families [1]. While work on the modern diversity of these familiar insects is well established, knowledge of their history has been hampered by the extremely scarce record of ectoparasites in general. For example, aside from lice on mummies or other subfossil corpses the single definite louse fossil was discovered and described only recently from the Eocene of Germany [2,3], and is remarkably modern in appearance as might be expected from a lineage that is presumably of mid-Mesozoic age. Similarly, fossil fleas

*Corresponding author (email: dyhuang@nigpas.ac.cn) have been confined almost entirely to Cenozoic amber [4,5], with the only the enigmatic Tarwinia from the Early Cretaceous of Australia as putatively the sole Mesozoic record [6,7], although attribution of these to Siphonaptera have been controversial until recently. Two further enigmatic apterous insects, namely Saurophthirus and Strashila, are known from the Early Cretaceous and the Late Jurassic of Tansbaikalia in Russian [8,9]. Saurophthirus has recently been considered to be a specialized flea, like Tarwinia [10]. The genus Saurophthiroides was initially considered a relative of Saurophthirus but was subsequently discovered to be a synonym of Chresmoda [11]. However, Strashila is not an ectoparasite at all according to our recent study, including an account of the hitherto unknown female [12]. Thus, the recently reported new Mesozoic giant fleas, with their fine preservation and representation by both sexes, provide sig- 
nificant new knowledge for understanding early ectoparasitism and siphonapteran evolution $[10,13]$. Three different forms of giant fleas were reported in Huang et al. [10] and informally named as Taxon $\mathrm{A}, \mathrm{B}$, and $\mathrm{C}$, these ranging in age from the Middle Jurassic to the Early Cretaceous. Their general characters were briefly described in the original paper, but without systematic description formal denomination. Subsequently, Gao et al. [13] proposed the family Pseudopulicidae for Pseudopulex and two included species. Here we describe the three forms of fleas which served as the basis for Huang et al. [10] and based on a detailed analysis of their morphology. In addition, we provide comments on the familial placement of Tarwinia.

\section{Material and methods}

A total of seven specimens are included in the present study. These are: two males and a female of Pseudopulex wangi $\mathrm{sp}$. nov., two females of Hadropsylla sinica gen. et sp. nov., both from the Middle Jurassic Daohugou beds at Daohugou Village, Ningcheng County, Inner Mongolia, and a male and a female of Tyrannopsylla beipiaoensis gen. et sp. nov. from the Early Cretaceous Yixian Formation at Huangbanjigou, Beipiao City, western Liaoning Province. The Middle Jurassic fleas are compressed in fine, greyish laminated volcanic tuffs. The Early Cretaceous fleas are preserved in strongly-weathered, yellowish laminated volcanic mud stones. All specimens are preserved as brownish films with slight three-dimensional preservation. The material is housed in the Nanjing Institute of Geology and Palaeontology (NIGP), Nanjing, China.

The fossils were prepared using a sharp knife. Photomicrographs were taken using a Zeiss Discovery V20 microscope system, and some of them (Figures 2(f), 3(e) and (f)) moistened with $70 \%$ alcohol, Figure 3(f) was created from a sequence of $Z$-stack images due to its three-dimensional structures. Macrophotography was undertaken using a Canon 5D Mark II digital camera. A large number of Recent fleas housed in the Field Museum of Natural History (Chicago) were checked by DYH for morphological comparison.

\section{Systematic palaeontology}

Class Insecta Linnaeus, 1758

Order Siphonaptera Latreille, 1825

Family Pseudopulicidae Gao, Shih \& Ren, 2012

Revised familial diagnosis. Large forms, female always larger than male; body more or less dorsoventrally flattened; antenna relatively compact, with at least 16 antennomeres (14-17 flagellomeres), piercing-suctorial siphonate mouthparts serrated and longer in female; thorax not greatly reduced; tibia armed with distinct apical ctenidia, tarsi elongate, at least as long as femora and tibia combined; body covered with posteriorly-directed setae; sensilium absent; male abdominal sternites sclerotized; male genitalia exposed and large, with elongate gonocoxa and one-segmented gonostylus.

Included genera. Pseudopulex (type genus), Hadropsylla gen. nov., and Tyrannopsylla gen. nov.

Genus Pesudopulex Gao, Shih \& Ren, 2012

Type species. Pesudopulex jurassicus Gao, Shih \& Ren, 2012.

Revised generic diagnosis. Female, antenna with at least 14-segmented compact flagellum; siphonate-serrated mouthparts at least extending anteriorly to metacoxae; distinct comb-like, apical ctenidia on pro- and mesotibiae; tarsi distinctly longer than femora and tibia together; body covered with posteriorly-directed setae and spines. Male, size smaller, antenna more slender; mouthparts short; fifth tarsomere large, abdominal sternites all sclerotized.

Remarks. Gao et al. [13] established two species within Pesudopulex, i.e. P. jurassicus and P. magnus. In the specific diagnosis it was indicated that $P$. jurassicus differs from $P$. magnus by the number of antennomeres, presence of tibial ctenidia, and lacinial serrations covering a larger surface in $P$. jurassicus. In the diagnosis for $P$. magnus it was conversely proposed that this species differs from $P$. jurassicus by the number and shape of the antennomeres, distinctly sharper maxillary laciniae, and much larger body size. However, all of the above differences are possibly altered during and resulting from preservation. The antenna of the type material of $P$. jurassicus has 16 visible antennomeres, and that of $P$. magnus has more than 16 antennomeres, statements that provide no critical differences. The presence of tibial ctenidia has already been indicated in Gao et al. [13], that it is not evident probably due to poor preservation in P. magnus and so this again does not serve to truly distinguish their taxa. The serrated teeth are arranged on both margins of the laciniae as in some modern fleas. The paired laciniae form a blood channel bearing a more or less tubular shape. Given this morphology, the number and form of the serrations present themselves differently in different orientations depending on preservation. This purported difference is therefore also suspect. The size of $P$. jurassicus (17.0 mm long) is distinctly smaller than that of $P$. magnus (22.8 $\mathrm{mm}$ long). This may represent a true specific difference between these taxa, but intraspecific size variability is well documented among Recent fleas, with recently fed individuals almost always much larger than those that are starved. Such a size difference is evidenced in our new species Hadropsylla sinica gen. et sp. nov. (vide infra); the holotype ( $20.6 \mathrm{~mm}$ long) is distinct longer than the paratype (17.8 $\mathrm{mm}$ long). Nevertheless, $P$. jurassicus can obviously be distinguished from $P$. magnus by having a much longer metafemur. The metafemora in P. magnus are nearly twice as long as the mesofemora, but these are only slightly longer than the mesofemora in P. jurassicus. This character, not mentioned in the original diagnoses, seems to 
be the most reliable distinction between these taxa. Herein we provide the description of a third species within the genus.

\section{Pesudopulex wangi sp. nov.}

Type material. Holotype (NIGP154244 a, b), a complete female with counterpart; allotype (NIGP154245), a complete male without counterpart; paratype (NIGP154246), an incomplete male without counterpart.

Etymology. The specific epithet, wangi, is a patronym for Xiangdong Wang (Beijing) who provided the specimen here designated as holotype for our research.

Diagnosis. Female, antenna with 14-segmented flagellum, relatively broad and distinctly compact; siphonate mouthparts slightly serrated, extending anteriorly to metacoxae; labial palp fused by four palpomeres; comb-like ctenidia present on apex of pro- and mesotibiae, scattered ctenidia present on metatibia. Male circa half long as female; antenna moniliform, relatively slender, with 14-segmented flagellum; mouthparts extending at most to mesocoxae; fifth tarsomere enlarged, armed with distinct bristles, pretarsal claws large.

Locality and horizon. Middle Jurassic Jiulongshan Formation at Daohugou, Ningcheng County, Inner Mongolia, China.

Description. Female, $14.8 \mathrm{~mm}$ long; body spindly in shape, widest section at abdominal segment IV (Figure 1 (a)). Head relatively small, more or less rounded; antennal socket developed; antenna 16-segmented, distinct compact, scape large, pedicel conical, flagellum short, widen backwards, broadest at middle section, rounded at apex (Figure 1 (f)); compound eyes moderate large, close to antennal socket; ocelli absent; mouthparts extending to base of metacoxae (Figure 1(b)), maxillary lacinia armed with tiny denticles (serrations), labial palpus with four fused palpomeres, as
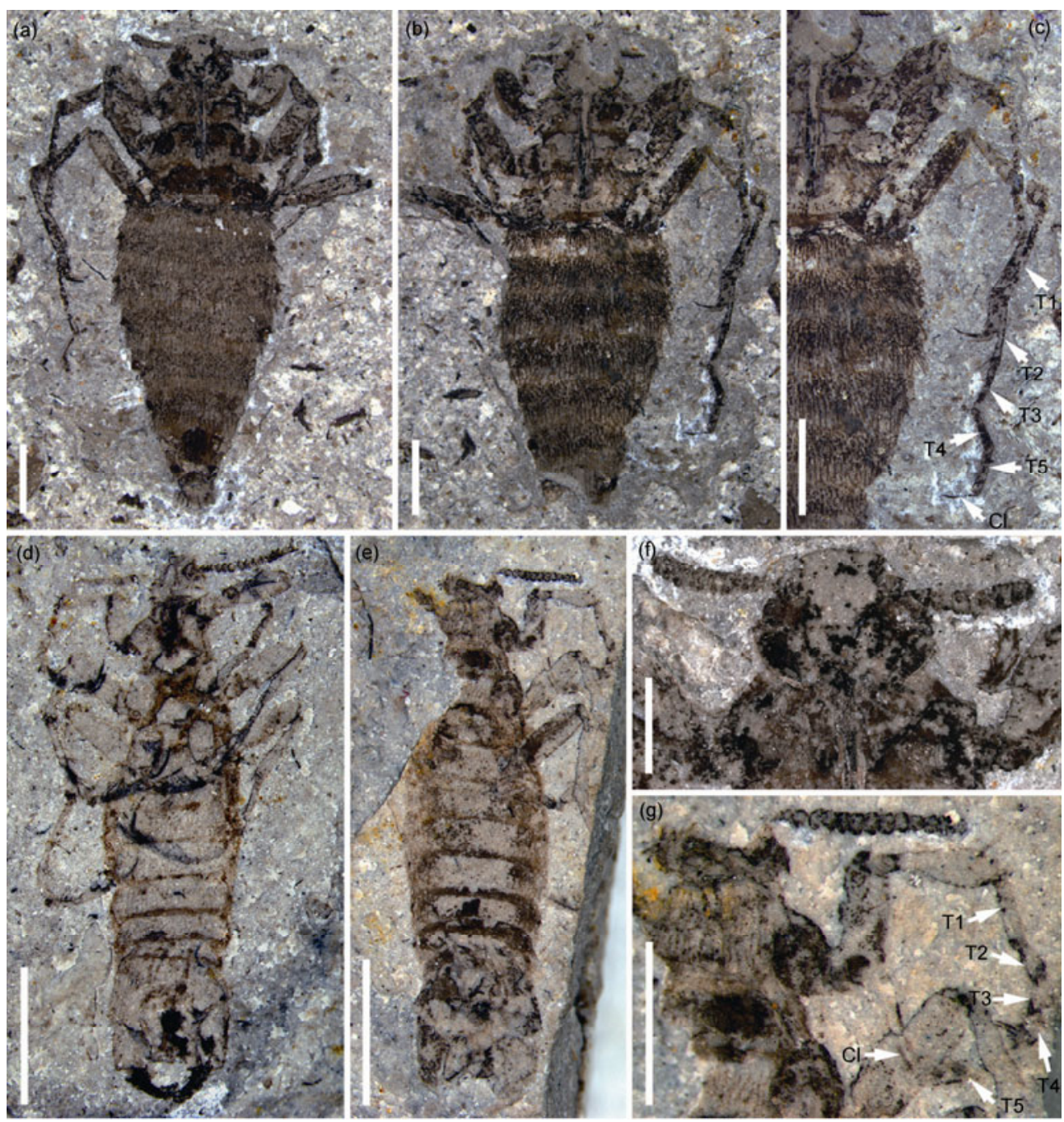

Figure 1 The Middle Jurassic giant flea Pesudopulex wangi sp. nov. from Daohugou, Ningcheng County, Inner Mongolia. Scale bars represent $1 \mathrm{~mm}$ in (f) and (g), $2 \mathrm{~mm}$ in (a)-(e). (a) The part of holotype (NIGP154244 a), a complete female showing the general habitus; (b) the counterpart (NIGP154244 b) of holotype; (c) enlargement from (b), showing details of the meso- and metatarsi; (d) allotype (NIGP154245), a complete male, showing the general habitus; (e) paratype (NIGP154246), an incomplete male, showing the general habitus; (f) enlargement from (a), showing details of the female head; (g) enlargement from (e), showing the antenna and fore legs of the male. T1-5, tarsomeres $1-5$; $\mathrm{Cl}$, claw. 
long as maxillary lacinia; maxillary palpus present but not clearly visible. Thorax armed with posteriorly-directed setae; pronotum narrower than mesonotum, mesonotum narrower than metanotum, approximately subequal in length, metafurcasternum distinct, between metacoxae; thoracic spiracles present; three pairs of similar legs, length distinctly increasing from forelegs to hind legs in femora, tibiae, and tarsi; coxae moderate large, widely separated (Figure 1(b)); femora robust, metafemora relatively slender, armed with a few transverse weak ctenedia; tibia slight curved, broaden after median section, armed with long setae, distinct comb-like ctenedia obliquely present near apex of pro- and mesotibiae, metatibiae with long and scattered setae in place of ctenedia; all tarsi pentamerous (5-segmented), armed with long setae, first tarsomere elongate, as long as second and third tarsomeres together, fourth tarsomere shortest, much shorter than third except on metatarsi, fifth tarsomere slightly longer than third; pretarsal claws long, slightly curved, and pointed (Figure 1 (c)). Abdomen poorly sclerotized with eight visible segments, segmentation not clearly divided, covered with posteriorly-directed ornamentation, spines arranged in anterior and middle sections, and long setae arranged in middle and posterior sections (Figure 1(b), (c)); eight pairs of small spiracles visible (Figure 1 (a)); elliptical pygidium present.

Male much smaller than female, approximately $8 \mathrm{~mm}$ long, body more elongate, winebottle-shaped (Figure 1(d), (e)). Head small; antenna 16-segmented, more or less moniliform, not greatly compact, scape and pedicel small, flagellum broadest at middle section, with rounded apex (Figure $1(\mathrm{~g})$ ); antennal socket developed; compound eyes close to antennal socket, moderately large; mouthparts relatively short, extending to position median between pro- and mesocoxae; maxillary lacinia pointed apically, labial palpus with four fused palpomeres, as long as maxillary lacinia; maxillary palp shorter, with pointed last segment. Thorax armed with posteriorly-directed setae, general features as in female, metafurcasternum distinct, between metacoxae; coxae relatively large, separated but relatively close to each other by comparison with female; femora robust, metafemur not much longer than mesofemur; tibiae broadened after median section, armed with oblique ctenedia in apicalmost section; all tarsi pentamerous, armed with long setae, first tarsomere very elongate, as long as second and third tarsomeres together, fourth tarsomere very short, triangular, fifth tarsomere greatly enlarged, widened at apex, armed with two rows of lateral plantar bristles (Figure $1(\mathrm{~g})$ ); pretarsal claws as in female except relatively larger. Abdomen well sclerotized, segmentation clearly divided, with eight segments, covered with some short posteriorly-directed setae, not densely arranged as in female; eight pairs of small spiracles visible (Figure 1(d), (e)); male genitalia exposed and large, strongly sclerotized, with elongate gonocoxa bearing a large, cylindrical, one-segmented, broad gonostylus articulated at apex to form a wide clasping organ (Figure 1(d), (e)).
Remarks. Some Recent fleas are sexually dimorphic with females always larger than males, and this situation also occurs in our Jurassic flea $P$. wangi sp. nov. The male allotype is only $8.0 \mathrm{~mm}$ long, slightly longer than half of the holotype $(14.0 \mathrm{~mm}$ long). The female and male display some distinct differences (e.g. antennal shape and length of mouthparts). The female correlates with the male mainly in the identical number of antennomeres. Their femora are relatively broad and tibiae are wider after the mid-section. Their maxillary lacinia is as long as the labial palpus, unlike the condition in P. jurassicus where it is shorter than the labial palpus and contrasting with Hadropsylla sinica gen. et sp. nov. in which it is longer than the labial palpus (vide infra). Moreover, the labial palpus is quite distinctive and has no clearly indicated palpomeres, with the non-straight margin suggesting the points of fusion. Thus, these males more justifiably correspond to the female of $P$. wangi $\mathrm{sp}$. nov. rather than to females of other species known from the Daohugou locality. Lastly, both of them have small abdominal spiracles and distinct metafurcasternum between metacoxae, features also not occurring in other described fleas from Daohugou.

The new species more generally resembles the Early Cretaceous $P$. magnus by antennal morphology and general tarsal characters. Pseudopulex magnus was supposedly from the Early Cretaceous Yixian Formation at Duolun Village, Duolun County, Inner Mongolia [13], but there is no 'Duolun Village' in that area. Therefore, the stratigraphic information on P. magnus requires confirmation.

Genus Hadropsylla gen. nov.

Type species. Hadropsylla sinica sp. nov.

Etymology. The generic name is a combination of the Greek terms hadros, 'large' or 'bulky', and psylla, 'flea'; the name is feminine.

Diagnosis. Female antenna with 19 antennomeres, flagellum relatively compact, pointed at apex; siphonate serrated mouthparts at least extending to second sternite; uniformly scattered ctenidia present apically on all tibiae; tarsi approximately as long as femora and tibia together; fourth tarsomere very small; body covered with posteriorlydirected long setae.

Hadropsylla sinica gen. et sp. nov.

Type material. Holotype, (NIGP 154257 a, b), a complete female with counterpart; paratype (NIGP 154258), a complete female without counterpart.

Etymology. The specific epithet, sinica, is a Latin reference to China.

Diagnosis. As for the genus (vide supra).

Locality and horizon. Middle Jurassic Jiulongshan Formation at Daohugou, Ningcheng County, Inner Mongolia, China.

Description. Female, larger one reaching $20 \mathrm{~mm}$ in length; body spindle-shaped, widest section at abdominal segment IV (Figure 2 (a), (c)). Head relatively small, more or less rounded; antennal socket developed; antenna with 19 

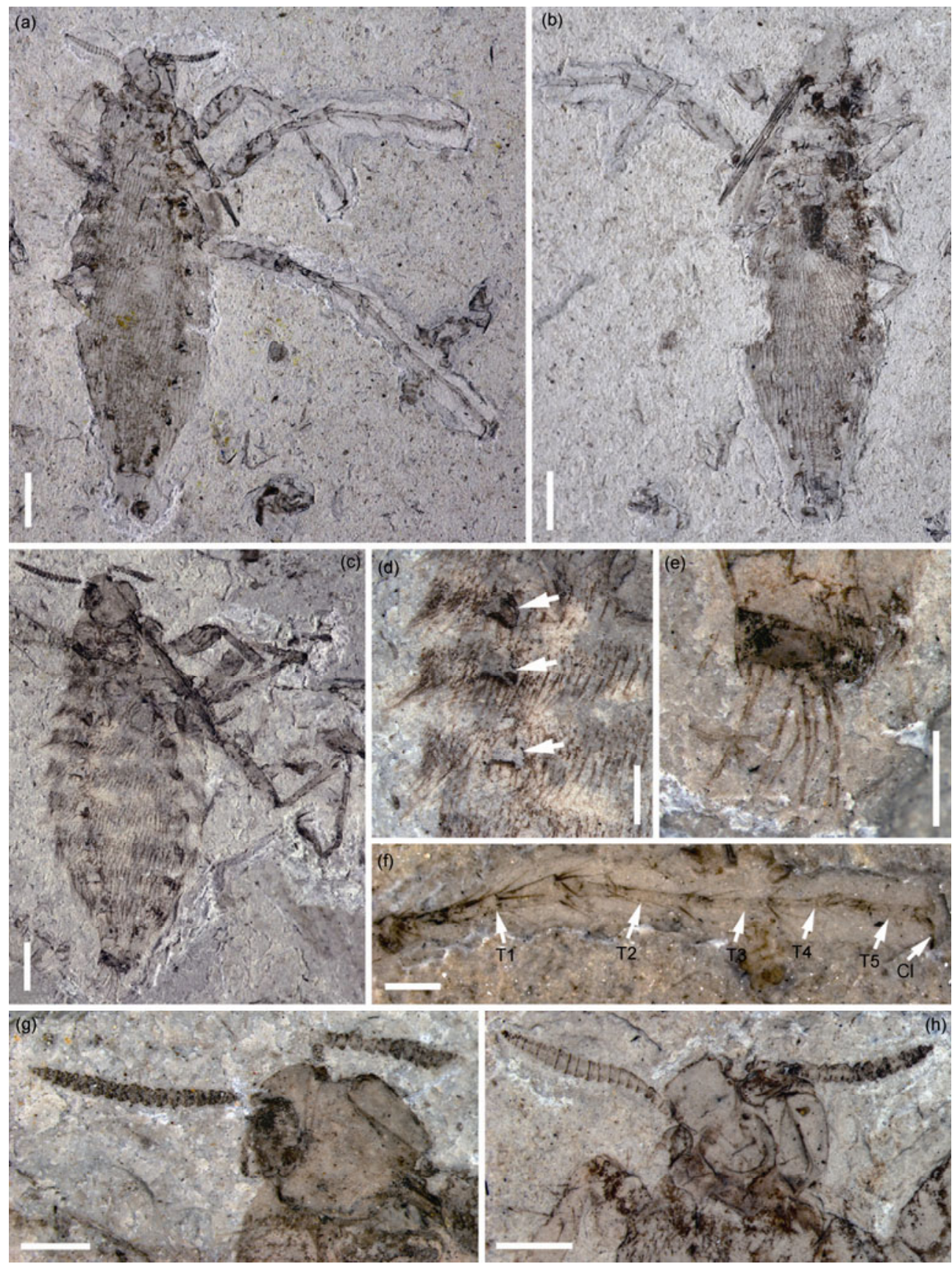

Figure 2 The Middle Jurassic giant flea Hadropsylla sinica gen. et sp. nov. from Daohugou, Ningcheng County, Inner Mongolia. Scale bars represent 1 $\mathrm{mm}$ in (d)-(h), $2 \mathrm{~mm}$ in (a)-(c). (a) The part of holotype (NIGP154247 a), a complete large female showing the general habitus; (b) the counterpart (NIGP154247 b) of holotype; (c) paratype (NIGP154248), a complete female, showing general habitus; (d) enlargement from (c), showing the posteriorly-directed setae and details of abdominal spiracles (arrows); (e) enlargement from (c), showing the female terminalia; (f) enlargement of (a), showing details of the hind tarsi; (g) enlargement from (c), showing details of the head; (h) enlargement from (a), showing additional details of the head.

antennomeres, relatively compact, scape long, pedicel slightly longer than flagellomere, flagellum broadest at middle section, tapering posteriorly, last flagellomere pointed (Figure $2(\mathrm{~g})$, (h)); compound eyes relatively small; ocelli absent; mouthparts prominent, maxillary lacinia serrated, with distinct lateral denticles arranged along entirety of lacinia; labial palpus flatten, palpomeres fused, slightly longer than maxillary lacinia, with more or less pointed apex (Figure 2 (b)); maxillary palpus short, tetramerous.
Thorax armed with posteriorly-directed, long setae; thoracic spiracles present; legs largely uniform, midlegs longer than forelegs, hind legs much longer than midlegs; coxae moderate large, widely separated; femora robust, metafemur long, armed with a few transverse weak ctenidia; tibia straight, gradually widened posteriorly, armed with long setae, a distinct transverse ctenidia present near apex of all tibiae with distinct scattered setae; all tarsi pentamerous, with long setae, first tarsomere elongate, as long as second and third 
tarsomeres together, fourth tarsomere very small, half as long as third tarsomere on mid and hind legs, fifth tarsomere slightly longer than third on fore and midlegs, slightly shorter than third on hind legs (Figure 2 (f)); pretarsal claws long, slightly curved, and pointed. Abdomen poorly sclerotized with eight visible segments, segments not clearly divided, covered with posteriorly-directed, long setae; eight pairs of large spiracles visible (Figure 2 (d)); female terminalia strongly sclerotized, armed with some long, pectinate bristles (Figure 2 (e)).

Discussion. The new genus differs markedly from $\mathrm{Pseu}$ dopulex by its number of antennomeres and antennal shape, longer mouthparts, details of tibial ctenidia, and much shorter tarsi. It resembles $P$. jurassicus in general characters, especially the antenna. Unfortunately, the apical antennomeres of $P$. jurassicus are not preserved. The tarsal characters of $P$. jurassicus have not been described in detail, but several obvious errors can be recognized from the original line drawings [13] and these must be addressed and revised before meaningful comparisons can be established.

\section{Genus Tyrannopsylla gen. nov.}

Type species. Tyrannopsylla beipiaoensis sp. nov.

Etymology. The generic name is a combination of the Greek terms tyrannos, 'tyrant' and psylla, 'flea'; the name is feminine.

Diagnosis of genus. Male, mouthparts extending to mesocoxae, serration not clearly visible on maxillary lacinia; scattered ctenidia present on apex of tibia; tarsi distinctly longer than femur and tibia together; abdominal sternite IV small but distinctly sclerotized, sternites V-IX strongly sclerotized. Female slightly larger than male; antenna with 17 antennomeres, more or less filiform; sternite VIII and IX strongly sclerotized.

Discussion. Tyrannopsylla differs from Pesudopulex and Hadropsylla in the number of antennomeres and antennal shape, length and morphology of mouthparts, and sclerotization of abdominal sternites. The genus particularly resembles the somewhat younger, Aptian-aged Tarwinia from Australia in the number of antennomeres and antennal shape $[4,6,7]$. The siphonate mouthparts were not described in Tarwinia, but such a structure appears to be present [4]. However, the body shape of Tarwinia is more or less laterally flattened, unlike the pseudopulicids which are somewhat dorsoventrally flattened. The tarsi are much longer than the femora and tibia combined in Tarwinia. Moreover, Tarwinia possesses very large marginal ctenidia on the proand metatibiae unlike those of pseudopulicids and there is a sensilium present (absent in pseudopulicids). Lastly, the posteriorly-directed abdominal setae are greatly reduced in number and space in Tyrannopsylla, more or less resembling that of many Recent forms, and differing from Tarwinia in that the Australian genus lacks such setae (vide infra).

Tyrannopsylla beipiaoensis gen. et sp. nov.

Type material. Holotype, (NIGP 154249 a, b), a com- plete male with counterpart; paratype (NIGP 154250), an incomplete female without counterpart, missing leg structures.

Etymology. The specific epithet, beipiaoensis, refers to the type locality.

Diagnosis. As for the genus (vide supra).

Locality and horizon. Early Cretaceous Yixian Formation at Huangbanjigou, Beipiao City, Liaoning Province, China.

Description. Male, $14.7 \mathrm{~mm}$ long, winebottle-shaped (Figure 3(a),(b)). Head small, posteriorly overlapped by pronotum; antenna approximately with 17 segments, more or less filiform, not greatly compacted, scape large, pedicel slightly larger than flagellum, flagellum uniform in shape (Figure 3(e)); antennal socket developed; mouthparts extending median position of meso- and metacoxae (Figure 3(a), (f)). Thorax armed with posteriorly-directed spines; posterior pronotum distinctly sclerotized, slightly narrower than mesonotum; middle legs slightly longer than fore legs, hind legs much longer than middle legs; coxae moderate large, separated but relatively close each other, metacoxae somewhat elongate (Figure 3(a)); femora robust, armed with setae; tibia gradually widened backwards, armed with arched ctenedia at the apex most section formed by scattered setae; all tarsi 5-segmented, armed with a few long setae, first tarsomere very elongate, approximately as long as second and third tarsomeres together, fourth tarsomere shortest, length of fifth tarsomere/third tarsomere distinct decreased from fore legs to hind legs; pretarsal claws relatively small and straight (Figure 3(a)). Abdomen covered with posteriorly-directed setae, relatively sparse, short setae arranged anteriorly, long setae arranged posteriorly on each segments (Figure 3(d)); abdominal sternites I-III vestigial, sternite IV small but sclerotized, sternites V-VIII strongly sclerotized, relatively large; sternite IX small, transverse, with small medioapical lobe; eight pairs of small spiracles visible (Figure 3(a), (d)); male genitalia exposed and large, strongly sclerotized, with elongate gonocoxa bearing a large, cylindrical, one-segmented broad gonostylus articulated at apex to form wide clasping organ, apparently with minute medituberculus and basituberculus in apical position, a distinct volsella present (Figure 3(a), (b))

Female slightly larger than male, $16.2 \mathrm{~mm}$ long, body spindle-shaped, widest section at abdominal segment III (Figure 3 (c)). Head relatively small, posteriorly overlapped by pronotum; antennal socket developed; antenna with 17 antennomeres, more or less filiform, not greatly compacted, scape large, pedicel larger than flagellomeres, flagellum uniform in shape, narrower than that of male, last flagellomere somewhat pointed at apex. Thorax armed with short spines; posterior portion of pronotum distinctly sclerotized, slightly narrower than mesonotum, with arched frontal edge; coxae apparently widely separated, most leg structures missing. Abdominal sternites I-VII poorly sclerotized, covered with posteriorly-directed setae, setae occupy only half 

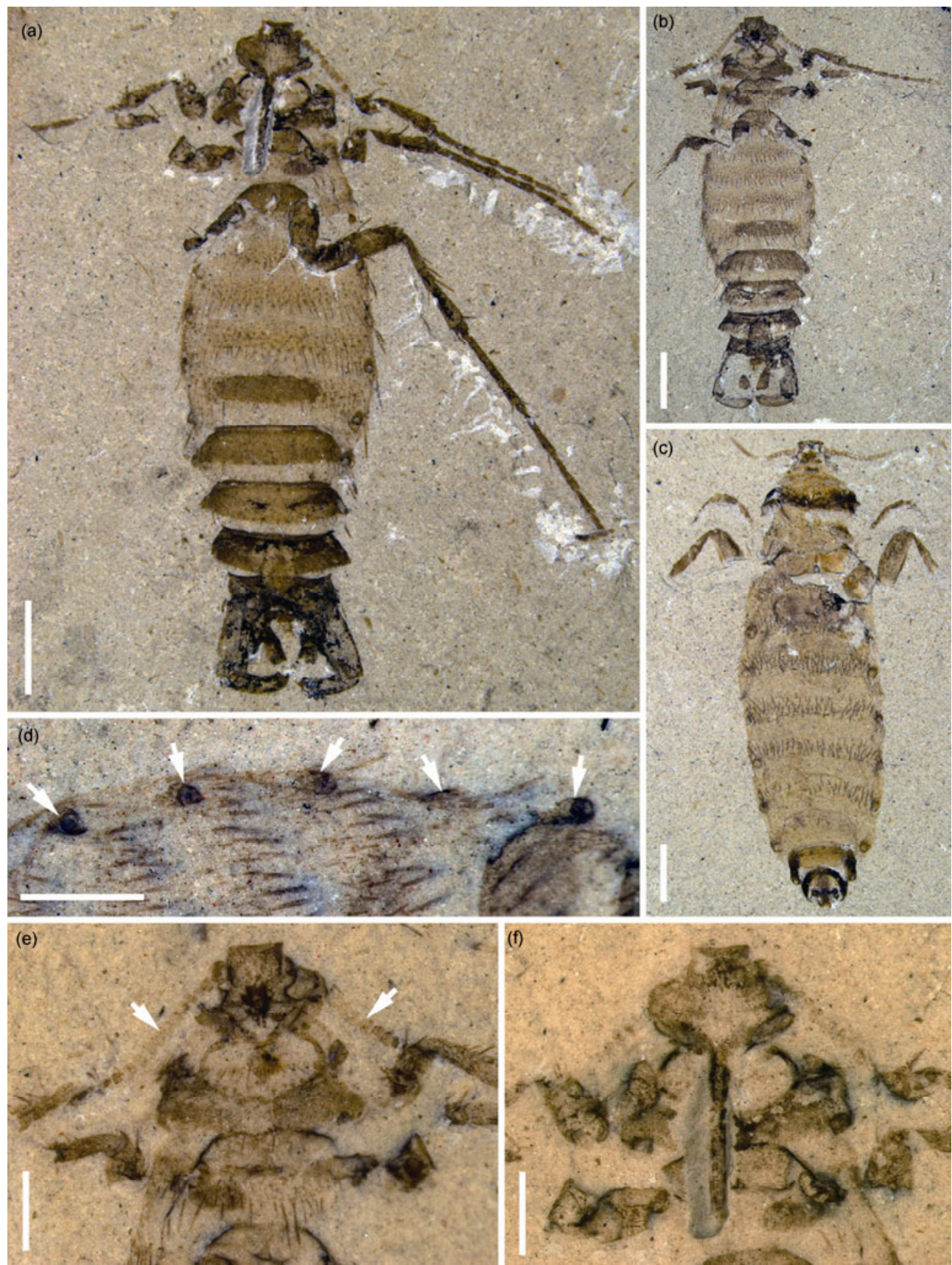

Figure 3 The giant flea Tyrannopsylla beipiaoensis gen. et sp. nov. from the Early Cretaceous Yixian Formation at Huangbanjigou, Beipiao City, Liaoning Province. Scale bars represent $1 \mathrm{~mm}$ in (d)-(f), $2 \mathrm{~mm}$ in (a)-(c). (a) The part of holotype (NIGP154249 a), a complete male showing the general habitus; (b) the counterpart (NIGP154249 b) of holotype; (c) paratype (NIGP154250), an almost complete female, showing general habitus; (d) enlargement from (a), showing the posteriorly-directed setae and details of abdominal spiracles (arrows); (e) enlargement from (b), showing the morphology of the antenna; (f) enlargement from (a), showing details of the mouthparts.

of surface of abdomen; sternites VIII and IX strongly sclerotized, without setae; eight pairs of small spiracles visible; female terminalia sclerotized, bristles not visible (Figure 3(e)).

Discussion. The female specimen of T. beipiaoensis exhibits relatively limited features. It correlates with the male in characters of the antenna and pronotum, and slightly larger size. Thus, the male and female of T. beipiaoensis are tentatively associated here but requires further corroboration by additional material in future.

Family Tarwiniidae fam. nov.

Type genus. Tarwinia Jell and Duncan, 1986.

Diagnosis. Moderately large, Early Cretaceous fleas. Maxillary palpus with four palpomeres; clypeus pointed; elongate siphonate mouthparts extending posteriorly only to mesthorax in male (based on undescribed material preserv- 
ing these features: unpubl. data); antenna with 15-segmented flagellum; compound eyes apparently reduced. Legs elongate, with generally slender podites, coxae not greatly enlarged although procoxae larger than in crown-group Siphonaptera; metatibia with distinctive ctenidia (vide Grimaldi and Engel [4]); pretarsal claws large. Abdomen without stout, posteriorly-directed setae; sensilium present.

Included genera. Tarwinia Jell and Duncan, 1986 from the Early Cretaceous of Australia.

\section{Conclusions}

The giant fleas of the Mesozoic were apparently ectoparasitic on hairy or feathered vertebrate hosts as evidenced by their large pretarsal claws, numerous posteriorly-directed setae, and scattered ctenidia on the body and legs $[10,13]$. They originated from siphonate mecopterans [10] and kept some ancestral characters such as relatively large size and dorsoventrally flattened body shape. The evolutionary trend for fleas displays an adaption for more freely moving among hairs/feathers of hosts. Therefore miniaturized size and laterally flattened outline evolved in their later remote evolutionary history. Candidate hosts are perhaps early mammals (such as multituberculates), feathered dinosaurs, and pterosaurs all of which occurred in the Middle Jurassic at Daohugou [14-18], as well as various beaked birds described from the Early Cretaceous Jehol fauna [19]. However, convincing evidence indicating an absolute host (e.g. mammals versus feathered dinosaurs) has not yet been forthcoming.

The hind legs of most Recent fleas are modified for jumping and have characteristically enlarged coxae and femora. All of the Mesozoic forms supposedly lacked the ability to jump [10,13]. Some Recent genera (e.g. Vermipsylla, Dorcadia) use comparably elongate, serrate mouthparts for fixing to their hosts [20]. Such elongate serrate mouthparts have evidently appeared in female pseudopulicids as documented herein. The coxae of male pseudopulicids are relatively elongate and relatively close each other unlike that of the female and loosely resemble some extant jumping forms. Their metafemora are robust unlike some females that bear strange elongate metafemora (e.g. $P$. magnus). It is perhaps possible that male pseudopulicids were more active than females, and may even have had a rudimentary jumping ability. This hypothesis remains speculative and will require corroboration by newly discovered material.

All of those fleas described from the Jurassic belong to the extinct family Pseudopulicidae, which ranges at least from the Middle Jurassic Daohugou fauna to the Early Cretaceous Jehol fauna. Saurophthirus (Saurophthiridae) represents another specialized flea reported from the Baissa fauna with a somewhat younger age than that of Jehol as evidenced by hemeroscopid dragonflies and caddisfly cases
$[21,22]$. And other forms, the tarwiniids, are known from the Aptian of Australia and other deposits. The presence of these disparate forms during the Early Cretaceous indicates that an initial radiation of primitive Siphonaptera had taken place during the earliest part of the Cretaceous or even the latest Jurassic. The disparate morphologies of these lineages suggest each was differently adapted to different kinds of hosts.

The food chain of vertebrates and invertebrates in the remote Mesozoic is poorly known, with only a few successfully documented cases. For example, the Middle Jurassic salamanders from Daohugou selectively fed on either corixids or conchostracans [23]. While the early fleas documented herein certainly fed on the blood of vertebrates, it remains a mystery as to precisely which lineage they victimized and how they might have affected individual hosts or even populations. For most Jurassic organisms their precise diet and ecological connections remain unknown and hinders our overall understanding of Mesozoic ecology.

Huang Diying is grateful to the Field Museum of Natural History (Chicago) for providing access to extensive material of Recent, slide-mounted fleas. This work was provided by the National Basic Research Program of China (2012CB821903), the National Natural Science Foundation of China (91114201 and 41222013), the Outstanding Youth Foundation of Jiangsu Province (BK2012049), and the Knowledge Innovation Program of the Chinese Academy of Sciences (KZCX2-YW-QN104), and U.S. National Science Foundation (DEB-0542909).

1 Whiting M F, Whiting A S, Hastriter M W, et al. A molecular phylogeny of fleas (Insecta : Siphonaptera): Origins and host associations. Cladistics, 2008, 24: 677-707

2 Dalgleish R C, Palma R L, Price R D, et al. Fossil lice (Insecta: Phthiraptera) reconsidered. Syst Entomol, 2006, 31: 648-651

3 Wappler T, Smith V S, Dalgleish R C. Scratching an ancient itch: An Eocene bird louse fossil. Proc R Soc B-Biol Sci, 2004, 271: S255S258

4 Grimaldi D, Engel M S. Evolution of the Insects. New York: Cambridge University Press, 2005. 470-491

5 Perrichot V, Beaucournu J C, Velten J. First extinct genus of a flea (Siphonaptera: Pulicidae) in Miocene amber from the Dominican Republic. Zootaxa, 2012, 3438: 54-61

6 Jell P A, Duncan P M. Invertebrates, mainly insects, from the freshwater Lower Cretaceous, Koonwarra Fossil Bed (Korumburra Group), South Gippsland, Victoria. Mem Assoc Australas Palaeontol, 1986, 3: 111-205

7 Riek E F. Lower Cretaceous fleas. Nature, 1970, 227: 746-747

8 Ponomarenko A G. A new insect from the Cretaceous of Transbaikalia, a possible parasite of pterosaurians. Paleontol J, 1976, 10: 339-343

9 Rasnitsyn A P. Strashila incredibilis, a new enigmatic mecopteroid insect with possible siphonapteran affinities from the Upper Jurassic of Siberia. Psyche, 1992, 99: 323-333

10 Huang D, Engel M S, Cai C, et al. Diverse transitional giant fleas from the Mesozoic era of China. Nature, 2012, 483: 201-204

11 Delclòs X, Nel A, Azar D, et al. The enigmatic Mesozoic insect taxon Chresmodidae (Polyneoptera): New palaeobiological and phylogenetic data, with the description of a new species from the Lower Cretaceous of Brazil. N Jb Geol Paläontol Abh, 2008, 247: 353-381

12 Huang D, Nel A, Cai C, et al. Amphibious files and paedomorphism in Jurassic period. Nature, 2013, 495: 94-97 
13 Gao T, Shih C, Xu X, et al. Mid-Mesozoic flea-like ectoparasites of feathered or haired vertebrates. Curr Biol, 2012, 22: 732-735

14 Ji Q, Luo Z, Yuan C, et al. A swimming mammaliaform from the Middle Jurassic and ecomorphological diversification of early mammals. Science, 2006, 311: 1123-1127

15 Luo Z, Ji Q, Yuan C. Convergent dental adaptations in pseudotribosphenic and tribosphenic mammals. Nature, 2007, 450: 93-97

16 Meng J, Hu Y, Wang Y, et al. A Mesozoic gliding mammal from northeastern China. Nature, 2006, 444: 889-893

17 Wang X, Zhou Z, Zhang F, et al. A nearly completely articulated rhamphorhynchoid pterosaur with exceptionally well-preserved wing membranes and "hairs" from Inner Mongolia, northeast China. Chin Sci Bull, 2002, 47: 226-230

18 Zhang F, Zhou Z, Xu X, et al. A bizarre Jurassic maniraptoran from
China with elongate ribbon-like feathers. Nature, 2008, 455: 11051108

19 Chang M M. The Jehol Biota: The emergence of feathered dinosaurs, beaked birds and flowering plants. Shanghai: Shanghai Scientific \& Technical Publishers, 2003. 1-208

20 Wu H. Fauna Sinica, Insecta, Siphonaptera (in Chinese). 2nd ed. Beijing: Science Press, 2007. 1-2174

21 Huang D, Lin Q. The Early Cretaceous hemeroscopid larva fossils from Beijing, China. Chin Sci Bull, 2001, 46: 1477-1481

22 Huang D, Wu H, Dong F. The discover and priliminary study of fossil caddis case in China (in Chinese). Acta Palaeontol Sin, 2009, 48: 646-654

23 Dong L, Huang D, Wang Y. Two Jurassic salamanders with stomach contents from Inner Mongolia, China. Chin Sci Bull, 2012, 57: 72-76

Open Access This article is distributed under the terms of the Creative Commons Attribution License which permits any use, distribution, and reproduction in any medium, provided the original author(s) and source are credited. 